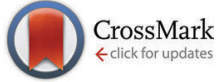

Cite this: J. Mater. Chem. C, 2015, 3, 7421

Received 28th May 2015,

Accepted 22nd June 2015

DOI: $10.1039 / c 5 t c 01529 d$

www.rsc.org/MaterialsC

\title{
Highly efficient acido-triggered reversible luminescent and nonlinear optical switch based on 5- $\pi$-delocalized-donor-1,3-di(2-pyridyl)benzenes
}

\author{
Filippo Nisic, ${ }^{a}$ Alessia Colombo, ${ }^{\star a}$ Claudia Dragonetti, ${ }^{a b}$ Mattia Fontani, ${ }^{a}$ \\ Daniele Marinotto, ${ }^{\mathrm{b}}$ Stefania Righetto, ${ }^{a}$ Dominique Roberto ${ }^{\mathrm{ab}}$ and \\ J. A. Gareth Williams*c
}

\begin{abstract}
The acidochromic behaviour of trans-5-( $p$-(N,N-diphenylamino)styryl)-1,3-di(2-pyridyl)benzene (1) and 5 -( $p$-(N,N-diphenylamino)phenylethynyl)-1,3-di(2-pyridyl) benzene (2) was investigated, both in solution and doped into films, studying their linear and nonlinear optical properties. Remarkably, the efficient luminescence of $\mathbf{1}$ drops drastically upon protonation and is restored upon deprotonation - both in solution and in the solid state - leading to an excellent on/off emissive acido-triggered reversible switch. In parallel, protonation leads to a large enhancement of the second-order NLO response, as determined by the EFISH technique, which is reversible upon deprotonation. The related methylated salts of $\mathbf{1}$ and $\mathbf{2}$ are similarly characterized by a high NLO response.
\end{abstract}

\section{Introduction}

Molecular systems with second-order nonlinear optical (NLO) properties are important as building block materials for optical communications, optical data processing and storage, or electrooptical devices. ${ }^{1}$ Among them, molecular species with commutable NLO properties are of increasing interest. ${ }^{2}$ Recently, research on the modulation of the electronic and optical properties of luminescent compounds using an external trigger has been extended to the field of nonlinear optics. It has been shown that the quadratic hyperpolarizability of molecular systems may be switched by reversibly modifying the properties of specific parts of active molecules. The on/off switching may be due to a reduction of the donor ability of the electron-rich fragment (D) of a typical push-pull donor-acceptor species, D-bridge-A, by oxidation or protonation. Conversely, the acceptor behaviour of A can be changed by reduction, or by deprotonation. Manipulation of the second-order NLO response may also be achieved through structural or chemical modification of the bridging group, thereby interfering with the communication between $\mathrm{D}$ and A. Accordingly, NLO switches can be realized by a redox process, by $\mathrm{pH}$ variation, or by interaction with electromagnetic radiation. ${ }^{2}$

\footnotetext{
${ }^{a}$ Dipartimento di Chimica dell'Università degli Studi di Milano,

UdR INSTM di Milano, Italy.E-mail: alessia.colombo@unimi.it

${ }^{b}$ ISTM-CNR, via Golgi 19, 20133 Milano, Italy

${ }^{c}$ Department of Chemistry, University of Durham, South Road, Durham, DH1 3LE,

UK. E-mail: j.a.g.williams@durham.ac.uk
}

Of particular interest are organic compounds which display considerable NLO variations due to their ability to alternate between two distinct chemical forms in response to protonation/deprotonation. The first studies on the NLO properties of acid-base couples were carried out by Das, ${ }^{3}$ who showed how it is possible to determine the dissociation constants of weak organic aromatic acids in solution by Hyper Rayleigh Scattering (HRS) ${ }^{4}$ measurements. Successively, different second-order NLO organic switches have been studied by the HRS technique. For instance, acidochromes based on benzimidazolo[2,3- $b]$ oxazolidines, ${ }^{5}$ benzazolo-oxazolidines ${ }^{6}$ and indolino[2,1- $\left.b\right]$ oxazolidines ${ }^{7}$ show a remarkable contrast in the NLO response due to the reversible transformation of the oxazolidine closed form into a zwitterionic open form by acidification. Various molecules containing a 4,5-dicyanoimidazole acceptor unit, an $N, N$-dimethylamino donor group, and a $\pi$-conjugated bridge have also been described as pH-triggered NLO switches. ${ }^{8}$ Some of the present authors have recently reported on the reversible switching of the photoluminescence and second-order NLO properties of a substituted stilbazole, namely diphenyl-(4-\{2-[4-(2-pyridin-4-yl-vinyl)-phenyl]-vinyl\}-phenyl)amine, upon exposure to $\mathrm{HCl}$ and $\mathrm{NH}_{3}$ vapours. ${ }^{9}$ By using this molecular system, it was shown for the first time that Electric Field Induced Second Harmonic generation (EFISH) ${ }^{10}$ measurements are a convenient method to probe a protonation/deprotonation NLO contrast. ${ }^{9}$ The remarkable acido-triggered reversible switching of the luminescence and nonlinear optical properties of (2-pyrene-1-ylvinyl)pyridine have also been described. ${ }^{11}$

Meanwhile, we have shown that related D-A structures incorporating 1,3-dipyridylbenzenes at one end - trans-5( $p$-(N,N-diphenylamino)styryl)-1,3-di(2-pyridyl)benzene (1) and 


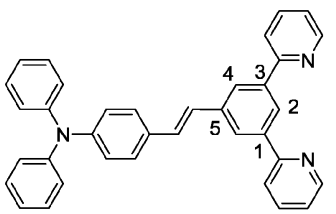

1

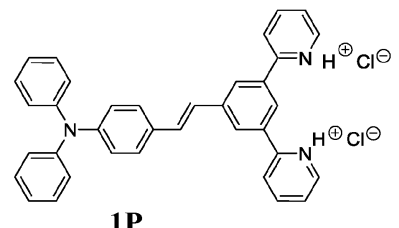

$1 \mathbf{P}$

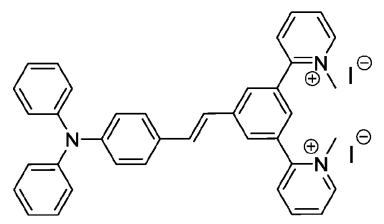

3

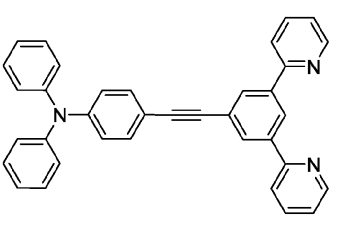

2

2P

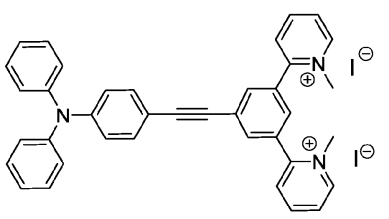

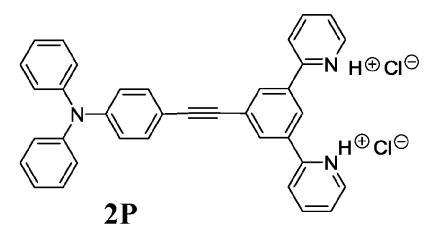

Fig. 15 - $\pi$-Delocalized-1,3-di(2-pyridyl)benzenes compounds investigated in this study for their linear and nonlinear optical properties.

5-( $p$-( $N, N$-diphenylamino)phenylethynyl)-1,3-di(2-pyridyl) benzene (2) (Fig. 1) - can be used as "pincer" proligands to generate $\mathrm{N}^{\wedge} \mathrm{C}^{\wedge} \mathrm{N}$-coordinated, cyclometallated platinum(II) complexes, which are of interest for the preparation of NIR-phosphorescent OLEDs for instance. ${ }^{12}$ The above results, and the growing interest in the design of compounds showing both luminescent and second-order NLO properties as new multifunctional materials for the design of molecular switches and molecular machines, ${ }^{13}$ prompted us to explore the modulation of the linear and nonlinear optical properties of $\mathbf{1}$ and $\mathbf{2}$ by protonation by $\mathrm{HCl}$ vapour, to give $\mathbf{1 P}$ and $\mathbf{2 P}$, and their reversible deprotonation using $\mathrm{NH}_{3}$ vapours (Fig. 1). We present here the results of this investigation, which has led to new, efficient acido-triggered reversible luminescent and NLO switches, as well as to novel salts ( 3 and 4 ) that are characterized by a high NLO response.

\section{Experimental}

\section{General comments}

Solvents were dried by standard procedures: THF was freshly distilled from $\mathrm{Na}$ /benzophenone under nitrogen atmosphere, $\mathrm{N}, \mathrm{N}$-dimethylformamide (DMF) was dried over activated molecular sieves and triethylamine $\left(\mathrm{Et}_{3} \mathrm{~N}\right)$ was freshly distilled over $\mathrm{KOH}$. All reagents were purchased from Sigma-Aldrich and were used without further purification. Reactions requiring anhydrous or oxygen-free conditions were performed under nitrogen. Thinlayer chromatography (TLC) was carried out using pre-coated Merck F254 silica gel plates. Flash chromatography was carried out with Macherey-Nagel silica gel 60 (230-400 mesh).

${ }^{1} \mathrm{H}$ and ${ }^{13} \mathrm{C}$ spectra were recorded at $400 \mathrm{MHz}$ on a Bruker AVANCE-400 instrument. Chemical shifts $(\delta)$ for ${ }^{1} \mathrm{H}$ and ${ }^{13} \mathrm{C}$ spectra are expressed in ppm relative to internal $\mathrm{Me}_{4} \mathrm{Si}$ as standard. Signals are abbreviated as s, singlet; bs, broad singlet; d, doublet; t, triplet; q, quartet; m, multiplet. Elemental analyses were performed using an Exeter Analytical E-440 analyser.

\section{Synthesis of compounds}

Neutral 1,3-di(2-pyridyl)benzene compounds $(1,2)$ and their protonated derivatives (1P,2P). Compounds trans $-5-(p-(N, N-$ diphenylamino)styryl)-1,3-di(2-pyridyl)benzene (1) and $5-(p-(N, N$ diphenylamino)phenylethynyl)-1,3-di(2-pyridyl)benzene (2) were prepared as reported in our previous study of their corresponding Pt(II) complexes, from the related 5-substituted 1,3-dibromobenzene. ${ }^{12}$ Further exposure of compounds 1 and 2, dissolved in $\mathrm{CHCl}_{3}$, to $\mathrm{HCl}$ vapours led immediately to the formation of 1P and 2P which were recovered in quantitative yield by evaporation of the solvent. Protonation of the pyridine moieties can also be performed in a few minutes by exposure to $\mathrm{HCl}$ vapours of 1 and 2 as powders. The reverse transformation can be induced by the treatment of protonated compounds, either in solution or as powder, with $\mathrm{NH}_{3}$ vapours for a few minutes. The time required for the protonation and deprotonation processes is related to the solution concentration, higher concentration solutions requiring longer time exposure to acid/base vapours. The protonation/deprotonation was easily monitored by absorption and emission spectroscopies, as described in the Results and Discussion section.

Data for trans-5-( $p$-( $N, N$-diphenylamino)styryl)-1,3-di(2-pyridyl)benzene (1). ${ }^{1} \mathrm{H}-\mathrm{NMR}\left(400 \mathrm{MHz}, \mathrm{CDCl}_{3}\right): \delta 8.76(2 \mathrm{H}, \mathrm{sb}), 8.46$ $(1 \mathrm{H}, \mathrm{s}), 8.23(2 \mathrm{H}, \mathrm{s}), 7.92(2 \mathrm{H}, \mathrm{d}, J=7.6 \mathrm{~Hz}), 7.83(2 \mathrm{H}, \mathrm{td}, J=$ $7.6 \mathrm{~Hz}, J=2.4 \mathrm{~Hz},), 7.43(2 \mathrm{H}, \mathrm{d}, J=8.4 \mathrm{~Hz}), 7.32-7.25(7 \mathrm{H}, \mathrm{m})$, $7.17(1 \mathrm{H}, \mathrm{d}, J=16.4 \mathrm{~Hz}), 7.13(4 \mathrm{H}, \mathrm{d}, J=8.4 \mathrm{~Hz}), 7.08-7.02$ (4H, m). ${ }^{13} \mathrm{C}-\mathrm{NMR}\left(100 \mathrm{MHz}, \mathrm{CDCl}_{3}\right): \delta 156.9,149.4,147.5,139.9$, 138.9, 137.2, 131.3, 129.3, 129.2, 127.5, 126.4, 125.6, 124.6, 124.4, 123.4, 123.1, 122.5, 121.1. Anal. calcd (\%) for $\mathrm{C}_{36} \mathrm{H}_{27} \mathrm{~N}_{3}$ : C 86.20, H 5.43, N 8.38. Found: C 86.23, H 5.41, N 8.35.

Data for 5-( $p$-( $N, N$-diphenylamino)phenylethynyl)-1,3-di(2pyridyl)benzene (2). ${ }^{1} \mathrm{H}-\mathrm{NMR}\left(400 \mathrm{MHz}, \mathrm{CDCl}_{3}\right): \delta 8.73(2 \mathrm{H}$, dd, $J=4.8 \mathrm{~Hz}, J=0.8 \mathrm{~Hz}), 8.59(1 \mathrm{H}, \mathrm{t}, J=1.6 \mathrm{~Hz}), 8.21(2 \mathrm{H}, \mathrm{d}$, $J=1.6 \mathrm{~Hz}), 7.87(2 \mathrm{H}, \mathrm{dt}, J=8.0 \mathrm{~Hz}, J=0.8 \mathrm{~Hz}), 7.79(2 \mathrm{H}, \mathrm{td}$, $J=8.0 \mathrm{~Hz}, J=1.6 \mathrm{~Hz}), 7.41(2 \mathrm{H}, \mathrm{d}, J=8.8 \mathrm{~Hz}), 7.31-7.26(6 \mathrm{H}, \mathrm{m})$, $7.13(4 \mathrm{H}, \mathrm{dd}, J=7.6 \mathrm{~Hz}, J=1.6 \mathrm{~Hz}), 7.07(2 \mathrm{H}, \mathrm{tt}, J=7.2 \mathrm{~Hz}$, $J=1.2 \mathrm{~Hz}), 7.03(2 \mathrm{H}, \mathrm{d}, J=8.8 \mathrm{~Hz}) .{ }^{13} \mathrm{C}-\mathrm{NMR}\left(100 \mathrm{MHz}, \mathrm{CDCl}_{3}\right)$ : $\delta$ 156.6, 149.7, 148.1, 147.3, 140.2, 136.9, 132.7, 130.4, 129.5, 125.2, 124.9, 123.7, 122.7, 122.4, 120.9, 116.1, 90.3, 88.6. Anal. calcd (\%) for $\mathrm{C}_{36} \mathrm{H}_{25} \mathrm{~N}_{3}$ : C 86.55, H 5.04, N 8.41. Found: C 86.61, H 5.03, N 8.37.

Data for (E)-2,2'-(5-(4-(diphenylamino)styryl)-1,3-phenylene)dipyridinium chloride (1P). ${ }^{1} \mathrm{H}-\mathrm{NMR}\left(400 \mathrm{MHz}, \mathrm{CD}_{3} \mathrm{OD}\right): \delta 8.89$ $(2 \mathrm{H}, \mathrm{d}, J=5.6 \mathrm{~Hz}), 8.55(2 \mathrm{H}, \mathrm{t}, J=8.0 \mathrm{~Hz}), 8.51-8.44(3 \mathrm{H}, \mathrm{m})$, $8.39(2 \mathrm{H}, \mathrm{d}, J=1.2 \mathrm{~Hz}), 7.95(2 \mathrm{H}, \mathrm{t}, J=7.0 \mathrm{~Hz}), 7.56-7.51(3 \mathrm{H}$, $\mathrm{m}), 7.37-7.28(5 \mathrm{H}, \mathrm{m}), 7.09(6 \mathrm{H}, \mathrm{d}, J=7.8 \mathrm{~Hz}), 7.04(2 \mathrm{H}, \mathrm{d}$, $J=12.4 \mathrm{~Hz}$ ).

Data for 2,2'-(5-((4-(diphenylamino)phenyl)ethynyl)-1,3phenylene)dipyridinium chloride (2P). ${ }^{1} \mathrm{H}-\mathrm{NMR}(400 \mathrm{MHz}$, $\left.\mathrm{CD}_{3} \mathrm{OD}\right): \delta 8.98(2 \mathrm{H}, \mathrm{t}, J=6.0 \mathrm{~Hz}), 8.83-8.75(2 \mathrm{H}, \mathrm{m}), 8.62-8.55$ $(2 \mathrm{H}, \mathrm{m}), 8.37(1 \mathrm{H}, \mathrm{d}, J=8.4 \mathrm{~Hz}), 8.20-8.15(2 \mathrm{H}, \mathrm{m})$, $7.97(1 \mathrm{H}, \mathrm{d}, J=1.2 \mathrm{~Hz}), 7.72(1 \mathrm{H}, \mathrm{d}, J=8.8 \mathrm{~Hz}), 7.46(1 \mathrm{H}, \mathrm{m})$, 
7.37-7.25 (5H, m), 7.14-7.10 (5H, m), $7.06(1 \mathrm{H}, \mathrm{d}, J=8.8 \mathrm{~Hz})$, $6.98(1 \mathrm{H}, \mathrm{d}, J=7.2 \mathrm{~Hz}), 6.92(1 \mathrm{H}, \mathrm{d}, J=8.0 \mathrm{~Hz})$.

General procedure for methylation of 1 and 2 to give 3 and 4 . Under a nitrogen atmosphere, a solution of 1 or $2(0.04 \mathrm{mmol})$ in methyl iodide $(0.5 \mathrm{~mL})$, was heated under reflux for $24 \mathrm{~h}$. After cooling to room temperature, the reaction mixture was filtered, and the precipitated salt (3 or 4) was washed with diethyl ether $(3 \times 5 \mathrm{~mL})$.

Data for $E-2,2^{\prime}$-(5-(4-(diphenylamino)styryl)-1,3-phenyl-ene)bis(1-methylpyridinium)iodide (3). Yield 85\%. ${ }^{1} \mathrm{H}-\mathrm{NMR}(400 \mathrm{MHz}$, $\left.\mathrm{CD}_{3} \mathrm{OD}\right): \delta 9.12(2 \mathrm{H}, \mathrm{d}, J=6.0 \mathrm{~Hz}), 8.72(2 \mathrm{H}, t, J=7.6 \mathrm{~Hz}), 8.24(2 \mathrm{H}$, $\mathrm{d}, J=8.0 \mathrm{~Hz}), 8.19(2 \mathrm{H}, \mathrm{t}, J=6.0 \mathrm{~Hz}), 8.14(2 \mathrm{H}, \mathrm{s}), 7.83(1 \mathrm{H}, \mathrm{s}), 7.52$ $(2 \mathrm{H}, \mathrm{d}, J=8.2 \mathrm{~Hz}), 7.47\left(1 \mathrm{H}, \mathrm{d}, J_{\text {trans }}=16.0 \mathrm{~Hz}\right), 7.33-7.30(4 \mathrm{H}, \mathrm{m})$, $7.27\left(1 \mathrm{H}, \mathrm{d}, J_{\text {trans }}=16.0 \mathrm{~Hz}\right) 7.09(6 \mathrm{H}, \mathrm{m}), 7.01(2 \mathrm{H}, \mathrm{d}, J=8.2 \mathrm{~Hz})$, 4.37 (6H, s). ${ }^{13} \mathrm{C}-\mathrm{NMR}$ (100 MHz, $\left.\mathrm{CD}_{3} \mathrm{OD}\right): \delta$ 155.9, 152.3, 149.9, 148.8, 148.2, 147.2, 142.2, 134.6, 133.9, 131.7, 131.4, 130.6, 130.4, $129.2,128.7,126.1,125.9,124.8,124.6,123.7,48.8$. Anal. calcd (\%) for $\mathrm{C}_{38} \mathrm{H}_{33} \mathrm{I}_{2} \mathrm{~N}_{3}$ : C 58.10, H 4.23, N 5.35. Found: C 58.0, $\mathrm{H} 4.24$, N 5.30.

Data for 2,2'-(5-((4-(diphenylamino)phenyl)ethynyl)-1,3phenylene)bis(1-methylpyridinium)iodide (4). Yield $83 \%$. ${ }^{1} \mathrm{H}-\mathrm{NMR}\left(400 \mathrm{MHz}, \mathrm{CD}_{3} \mathrm{OD}\right): \delta 9.13(2 \mathrm{H}, \mathrm{d}, J=6.0 \mathrm{~Hz}), 8.73$ $(2 \mathrm{H}, \mathrm{t}, J=8.0 \mathrm{~Hz}), 8.23(2 \mathrm{H}, \mathrm{d}, J=8.0 \mathrm{~Hz}), 8.19(2 \mathrm{H}, \mathrm{d}, J=6.4 \mathrm{~Hz})$, $8.11(2 \mathrm{H}, \mathrm{d}, J=1.6 \mathrm{~Hz}), 7.98(1 \mathrm{H}, \mathrm{s}), 7.41(2 \mathrm{H}, \mathrm{d}, J=8.8 \mathrm{~Hz}), 7.34$ $(4 \mathrm{H}, \mathrm{t}, J=8.0 \mathrm{~Hz}), 7.15-7.11(6 \mathrm{H}, \mathrm{m}), 6.97(2 \mathrm{H}, \mathrm{d}, J=8.8 \mathrm{~Hz})$, 4.35 (6H, s). ${ }^{13} \mathrm{C}-\mathrm{NMR}$ (100 MHz, $\left.\mathrm{CD}_{3} \mathrm{OD}\right): \delta 146.9,145.8,133.8$, 132.4, 130.2, 129.3, 128.6, 127.4, 125.2, 124, 120.9, 47.9. Anal. calcd (\%) for $\mathrm{C}_{38} \mathrm{H}_{31} \mathrm{I}_{2} \mathrm{~N}_{3}$ : C 58.25, H 3.99, N 5.36. Found: C 58.3, H 3.98, N 5.34.

\section{Preparation of thin films}

Thin films of the chromophores (1, 1P, 2 or $2 \mathbf{P})$ dispersed in polymethylmethacrylate (PMMA) or polystyrene were prepared by spin coating a few drops of a dichloromethane solution (chromophore/PMMA or polystyrene $=5 \mathrm{wt} \%$; PMMA or polystyrene $=10 \mathrm{wt} \%$ with respect to the solvent) on a glass substrate (thickness $1 \mathrm{~mm}$ ) previously cleaned with water/acetone. Parameters of spinning (RPM = revolutions per minute) RPM 1: 700; Ramp 1: $1 \mathrm{~s}$, Time 1: 5 s; RPM 2: 1000; Ramp 2: 5 s, Time 2: $10 \mathrm{~s}$; RPM 3: 1000; Ramp 3: $1 \mathrm{~s}$, Time 3: $10 \mathrm{~s}^{14}$

\section{Photophysical measurements}

Absorption spectra were recorded for solutions of the compounds in dichloromethane, in $1 \mathrm{~cm}$ pathlength quartz cuvettes using a Biotek Instruments XS spectrometer. Luminescence spectra in solution were recorded using a FluoroMax-2 spectrofluorimeter equipped with an R928 photomultiplier tube. The spectra of the films were obtained by mounting at an angle of $55^{\circ}$. Spectra were corrected for the wavelength dependence of the detector and emission grating. Quantum yields were determined using as standard a solution of quinine sulfate in $1 \mathrm{M} \mathrm{H}_{2} \mathrm{SO}_{4}(\mathrm{aq})(\Phi=0.548) .{ }^{15}$ The luminescence lifetimes were measured by time-correlated single-photon counting, following excitation with a pulsed laser diode at $374 \mathrm{~nm}$. The emitted light was detected at $90^{\circ}$ using a Peltier-cooled R928 photomultiplier tube after passage through a monochromator.

\section{EFISH measurements}

EFISH measurements were carried out in $\mathrm{CHCl}_{3}$ solutions at a concentration of $8 \times 10^{-4} \mathrm{M}$, with a non-resonant incident wavelength of $1.907 \mu \mathrm{m}$, obtained by Raman-shifting the fundamental $1.064 \mu \mathrm{m}$ wavelength produced by a Q-switched, modelocked $\mathrm{Nd}^{3+}$ :YAG laser manufactured by Atalaser. The apparatus used for EFISH measurements is a prototype made by SOPRA (France). The $\mu \beta_{\text {EFISH }}$ values reported are the mean values of 16 measurements performed on the same sample. The sign of $\mu \beta$ is determined by comparison with the solvent $\left(\mathrm{CHCl}_{3}\right)$.

\section{SHG measurements}

Second Harmonic Generation (SHG) experiments were performed using a Q-switched Nd:YAG (Quanta System Giant G790-20) laser at $1.064 \mu \mathrm{m}$ wavelength with a pulse of $7 \mathrm{~ns}$ and $20 \mathrm{~Hz}$ repetition rate. For poling measurements, the fundamental beam $(0.55 \mathrm{~mJ}$ for pulse) was polarized in the plane of incidence (p-polarized) and focused with a lens $(f=600 \mathrm{~mm})$ on the sample with an angle of about $55^{\circ}$ in order to optimize the SHG signal. The sample was placed over the hot stage whose temperature was controlled by a GEFRAN 800, while the corona wire voltage was applied by a TREK610E high-voltage-supply. Rejection of the fundamental beam was performed by an interference filter and a glass cut-off filter, and the p-polarized SHG signal at $532 \mathrm{~nm}$ was detected with a UV-Vis Hamamatsu C3830 photomultiplier tube. The corona poling process was carried out at $9.5 \mathrm{kV}$ while increasing the temperature at a rate of $2.3{ }^{\circ} \mathrm{C} \min ^{-1}$ up to $55{ }^{\circ} \mathrm{C}$ inside a specially built dry box, in $\mathrm{N}_{2}$ atmosphere. The temperature was maintained at $55{ }^{\circ} \mathrm{C}$ for $30 \mathrm{~min}$ and then decreased to room temperature. The setup for Maker fringe measurements was similar to the previous except that the fundamental beam was attenuated to $1 \mathrm{~mJ}$ for pulse and the sample was placed over a rotation stage. ${ }^{14}$

\section{Results and discussion}

Compounds trans-5-( $p$-(N,N-diphenylamino)styryl)-1,3-di (2-pyridyl)benzene (1) and 5-( $p$-(N,N-diphenylamino)-phenyl-ethynyl)-1,3di(2-pyridyl)benzene (2) were readily synthesized from 5 -substituted $m$-dibromobenzene derivatives, as previously reported. ${ }^{12} \mathrm{We}$ found that these pyridyl-containing compounds are converted to their protonated forms (1P and $\mathbf{2 P}$ ) by simple exposure to $\mathrm{HCl}$ vapour, whilst the reverse transformation occurs by further treatment with $\mathrm{NH}_{3}$ vapour. These protonation/deprotonation reactions take place rapidly, either in solution or in the solid state (powder and films; see Experimental).

\section{(i) Photophysical properties}

Absorption and photoluminescence data of 1, 2, 1P and 2P in solution are presented in Table 1 . The absorption spectra of 1 and 2 (Fig. 2) show very intense bands in the UV region $(\lambda<$ $400 \mathrm{~nm}$ ), due to spin-allowed ${ }^{1} \pi-\pi^{*}$ transitions. ${ }^{12}$ Upon protonation, a new band appears at significantly lower energies in both cases (Fig. 2 and Table 1). This change upon protonation is likely to arise from transitions having intramolecular 
Table 1 Photophysical data and second-order NLO properties of compounds 1, 1P, 2 and $\mathbf{2 P}$

\begin{tabular}{|c|c|c|c|c|c|}
\hline \multirow[b]{2}{*}{ Compound } & \multirow[b]{2}{*}{$\operatorname{Absorption}^{a} \lambda_{\max } / \mathrm{nm}\left(\varepsilon / \mathbf{M}^{-1} \mathrm{~cm}^{-1}\right)$} & \multicolumn{3}{|c|}{ Emission $298 \mathrm{~K}^{b}$} & \multirow{2}{*}{$\begin{array}{l}\text { Second-order NLO } \\
\text { response }^{c} \mu \beta / 10^{-48} \text { esu }\end{array}$} \\
\hline & & $\lambda_{\max } / \mathrm{nm}$ & $\tau \mathrm{ns}$ & $\Phi_{\text {lum }}$ & \\
\hline 1 & 260 (32 800), 286 (40 200), 375 (33 300) & $459[442]$ & $2.5\left[1.0,2.7(50 / 50)^{e}\right]$ & 0.92 & 102 \\
\hline 2 & 252 (41 900), 282 (42 200), 359 (38 400) & $430[426]$ & $2.4\left[1.0,4.0(40 / 60)^{e}\right]$ & 0.82 & 170 \\
\hline $2 \mathbf{P}$ & $292(46300), 361(20100), 418 \mathrm{sh}(33300)$ & $-^{d}[550]$ & $-{ }^{d}$ & $-^{d}$ & 406 \\
\hline
\end{tabular}

${ }^{a}$ In $\mathrm{CH}_{2} \mathrm{Cl}_{2} \cdot{ }^{b}$ Data in bold for $\mathrm{CH}_{2} \mathrm{Cl}_{2}$ solution; data in [parenthesis] refers to PMMA films. ${ }^{c}$ In $\mathrm{CHCl}_{3} .{ }^{d}$ No emission detectable in solution. ${ }^{e}$ Decay kinetics in films fitted to biexponential decay; corresponding pre-exponential factors in (parenthesis).
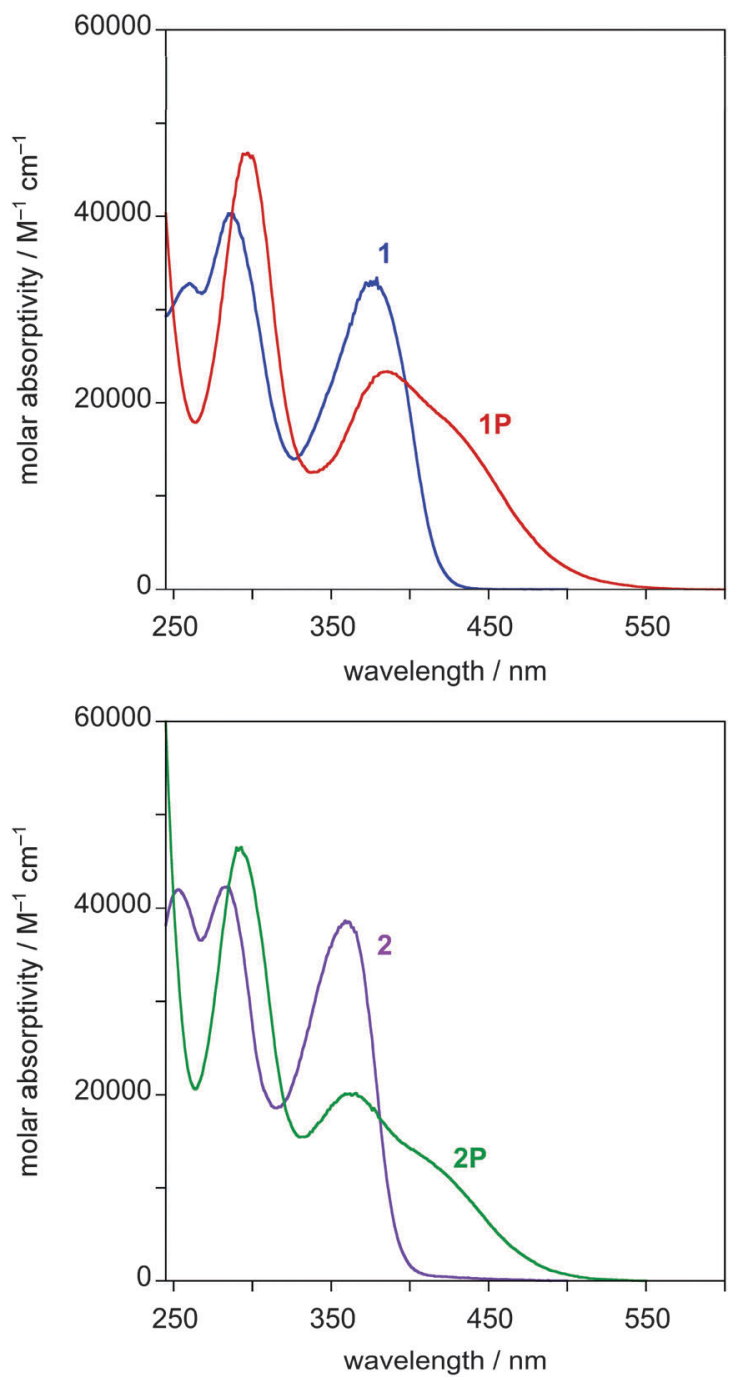

Fig. 2 Top: Absorption spectra of compound $\mathbf{1}$ in $\mathrm{CH}_{2} \mathrm{Cl}_{2}$ at $298 \mathrm{~K}$ before (blue) and after protonation (red). Bottom: Corresponding spectra of compound $\mathbf{2}$ (purple and green lines respectively).

charge-transfer character: protonation of the pyridyl rings as in 1P and $2 \mathbf{P}$ will increase the acceptor nature of the dipyridylbenzene moiety compared to $\mathbf{1}$ and 2 . Further treatment with $\mathrm{NH}_{3}$ vapour restores the original spectra in both cases.

Both compounds are intensely fluorescent in solution at room temperature: 1 emits in the blue region of the spectrum $\left(\lambda_{\max }=459 \mathrm{~nm}\right)$ with a luminescence quantum yield $\Phi$ of 0.92 , whilst the emission of 2 is blue/violet in colour $\left(\lambda_{\max }=430 \mathrm{~nm}\right.$, $\Phi=0.82$ ), somewhat blue-shifted compared to that of 1 (Fig. 3). The fluorescence lifetimes are between 2 and 3 ns. Interestingly, upon protonation, the extraordinarily intense of both $\mathbf{1}$ and $\mathbf{2}$ is completely quenched in solution: no emission is detectable in solution at room temperature (Fig. 3). Since the fluorescence of pyridinium salts (and those of related heterocycles) can be quenched by halide ions through a photoinduced electron
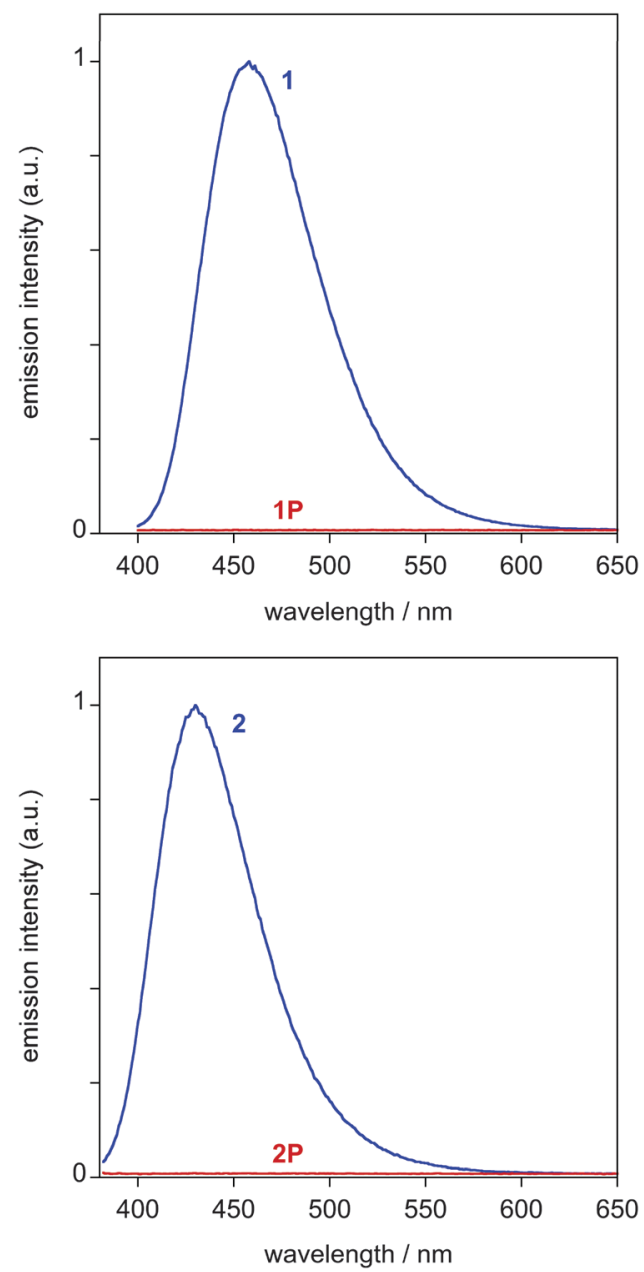

Fig. 3 Emission spectra of compounds $\mathbf{1}$ (top) and $\mathbf{2}$ (bottom) in $\mathrm{CH}_{2} \mathrm{Cl}_{2}$ at $298 \mathrm{~K}$ before protonation (blue lines), and after protonation with TFA (red lines). The starting spectra are restored upon exposure to $\mathrm{NH}_{3}$. The samples were excited at the isosbestic points in each case $\left(\lambda_{\text {ex }}=397 \mathrm{~nm}\right.$ for $1,381 \mathrm{~nm}$ for 2 ). 
transfer process, ${ }^{16}$ the response to trifluoroacetic acid (TFA) was also tested. This acid, too, led to the complete loss of the emission, indicating that the effect is associated exclusively with protonation. The response is different from that of related donor-acceptor terpyridines (featuring $\mathrm{N}^{\wedge} \mathrm{N}^{\wedge} \mathrm{N}$ terminal moieties), where emission is retained upon protonation, albeit weaker and shifted to lower energy. ${ }^{17}$ The on-off switching of the emission is exceptionally dramatic, given the high quantum yield of the unprotonated state and the complete absence of emission in the protonated form.

The emission switching behaviour was also investigated for films of 1 and 2 in polymethylmethacrylate (PMMA; 5 wt\%), prepared by spin-coating on a glass substrate. The two compounds emit in films at similar wavelengths to those in solution (Table 1). The fluorescence no longer displays monoexponential temporal decay kinetics, as it did in solution, but fits to a biexponential decay. Most probably, this simply reflects heterogeneity of the sample, and multiple environments of the emissive compounds within the films, such that the lifetime values under these conditions have little meaning.

Upon exposure to $\mathrm{HCl}$ vapour, in the case of the film of $\mathbf{1}$, there is again a dramatic decrease in the intensity of fluorescence, as seen visually in the photographs in Fig. 4. However, in contrast to solution, some weak green emission is detectable using the fluorimeter, with a $\lambda_{\max }$ of $555 \mathrm{~nm}$ (Fig. 5). Presumably, in the film, the deactivation processes that quench the emission of 1P so efficiently in solution are retarded within the more rigid PMMA matrix to an extent sufficient to allow some emission to be observed. In the case of the film of 2 , the behaviour is broadly similar to $\mathbf{1}$, although in this case, the emission of the protonated form is comparatively brighter.

\section{(ii) Second-order nonlinear optical properties}

We applied the EFISH method to study the NLO response in solution of 1, 2, 1P and 2P. This technique ${ }^{10}$ can provide direct information on the intrinsic molecular NLO properties, through

$$
\gamma_{\mathrm{EFISH}}=\left(\mu \beta_{\mathrm{EFISH}} / 5 k T\right)+\gamma(-2 \omega ; \omega, \omega, 0)
$$

where $\mu \beta_{\mathrm{EFISH}} / 5 k T$ is the dipolar orientational contribution to the molecular nonlinearity, and $\gamma(-2 \omega ; \omega, \omega, 0)$, the third order polarizability, is a purely electronic cubic contribution to $\gamma_{\mathrm{EFISH}}$ which can usually be neglected when studying the second-order NLO properties of dipolar compounds. Although it has traditionally been used to study charge-neutral molecules, the EFISH technique can be applied to the determination of the second-order NLO response of ionic species by working in a

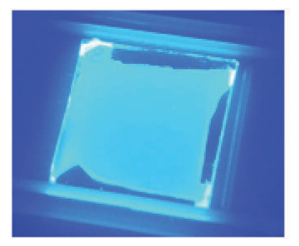

$$
\underset{\mathrm{NH}_{3 \text { vap. }} 30 \mathrm{~s}}{\stackrel{\mathrm{HCl}_{\text {vap. }} 30 \mathrm{~s}}{\rightleftarrows}}
$$

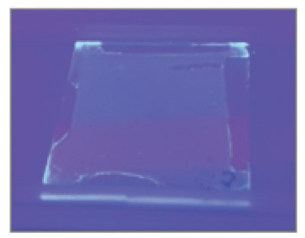

Fig. 4 Photograph of the protonated and unprotonated thin film of 1 : PMMA under UV light.
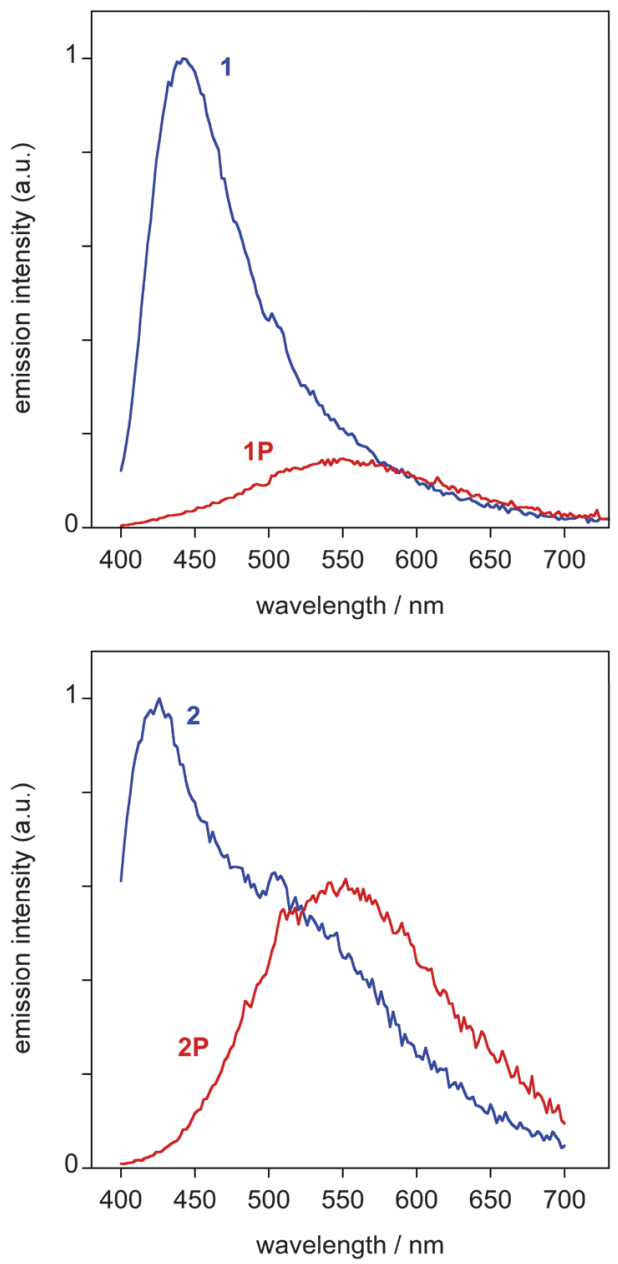

Fig. 5 Emission spectra of 1 : PMMA (top) and 2 : PMMA (bottom) films at $298 \mathrm{~K}$ before and after exposure to $\mathrm{HCl}$ (blue and red lines respectively).

solvent of low dielectric constant which favours ion-pairing. ${ }^{18}$ We found that 1 is characterized by a low value of $\mu \beta_{\mathrm{EFISH}}$ $\left(102 \times 10^{-48}\right.$ esu, see Table 1$)$ working in $\mathrm{CHCl}_{3}$ with a nonresonant incident wavelength of $1.907 \mu \mathrm{m}$. The positive value of $\mu \beta_{\text {EFISH }}$ is in agreement with an increase of the excited state dipole moment with respect to the ground state. ${ }^{19}$ The NLO response increases by a factor of $8.2\left(\mu \beta_{\mathrm{EFISH}}=840 \times 10^{-48} \mathrm{esu}\right.$, see Table 1) upon protonation in situ by $\mathrm{HCl}$ vapour, in agreement with the red-shift of the absorption spectrum (Table 1) caused by an increase of the acceptor properties of the pyridine moieties. Further exposure to $\mathrm{NH}_{3}$ vapours restores (after filtration of the solution to remove $\mathrm{NH}_{4} \mathrm{Cl}$ ) the original value. Remarkably, this enhancement factor (EF) of 8.2 is much higher than that recently reported for a related acido-triggered NLO switch based on a substituted stilbazole $(\mathrm{EF}=1.5),{ }^{9}$ showing the particular relevance of 1 as an NLO switch (Fig. 6). The second-order NLO response of 2 also increases upon protonation, as expected, but the enhancement factor is lower $(\mathrm{EF}=2.4$; Table 1$)$.

The high nonlinear optical response of $\mathbf{1 P}$ and $2 \mathbf{P}$ prompted us to prepare the related methylpyridinium iodide salts 3 and 4 in order to study their NLO properties. As expected, these are characterized by large $\mu \beta_{\text {EFISH }}$ values $\left(1280 \times 10^{-48}\right.$ and 


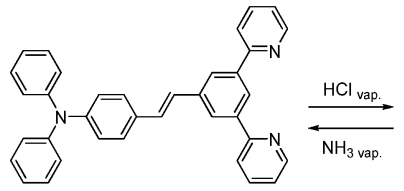

1

Emission on

Low NLO response

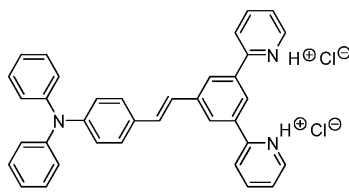

$1 P$

Emission off

High NLO response
Fig. 6 Linear and nonlinear optical reversible switch associated with protonation of the pyridyl rings.

$840 \times 10^{-48} \mathrm{esu}$, for 3 and 4 respectively). It is worth pointing out the large enhancement factor of the $\mu \beta_{\text {EFISH }}$ value of 1 upon alkylation $(\mathrm{EF}=10)$, much higher than that previously observed upon alkylation of substituted stilbazoles $(\mathrm{EF}=3.6){ }^{20}$

From the point of view of applications in NLO switching, compound 1P is of particular interest due to its high $\mu \beta_{\mathrm{EFISH}}$ value and to the high NLO contrast observed upon deprotonation in solution. Therefore we produced composite thin films of 1P and $\mathbf{1}$ in PMMA and polystyrene and studied the Second Harmonic Generation (SHG) signal of the resulting poled hostguest systems (see Experimental section). The chromophores readily lost their orientation in PMMA, as shown by a rapid decrease of the SHG signal, whereas a much better stability was reached by using the polystyrene matrix, as previously observed for other NLO compounds. ${ }^{14 a, b}$ A second-order NLO coefficient, $d_{33}$, of $0.22 \mathrm{pm} \mathrm{V}^{-1}$ was obtained for the $1 \mathbf{P}$ : polystyrene poled film. Treatment of the film with $\mathrm{NH}_{3}$ vapour to give 1 : polystyrene reduces the $d_{33}$ value to $0.10 \mathrm{pm} \mathrm{V}^{-1}$. A similar second-order NLO response was obtained after poling of a composite film prepared from 1 and polystyrene.

\section{Conclusions}

In summary, this work has shown how it is possible to switch the luminescence and nonlinear optical properties of $5-\pi$ delocalized-donor-1,3-di(2-pyridyl)benzenes through protonation. Remarkably, the very intense fluorescence of $\mathbf{1}$ drops drastically upon protonation but is restored upon deprotonation, both in solution and in the solid state, leading to an excellent neat on/off emissive acido-triggered reversible switch. In parallel, protonation leads to a large enhancement of the second-order NLO response in solution, as determined by the EFISH technique, which is reversible upon deprotonation. Related methylated salts are also characterized by a high NLO response. Interestingly $\mathbf{1 P}$ can be dispersed in a polystyrene matrix to give thin films characterized by a switchable second harmonic generation. Simple 1,3-di(2pyridyl)benzenes emerge as interesting multifunctional materials for the design of molecular switches.

\section{Acknowledgements}

This work was supported in Italy by MIUR (FIRB 2003: RBNE033KMA and FIRB 2004: RBPR05JH2P) and in the U.K. by Durham University.

\section{Notes and references}

1 J. Zyss, Molecular Nonlinear Optics: Materials, Physics and Devices, Academic Press, Boston, 1994.

2 (a) B. J. Coe, in Non-Linear Optical Properties of Matter, ed. M. G. Papadopoulos, A. J. Sadlej and J. Leszczynski, Springer Verlag, Berlin, 2006, p. 571; (b) V. Guerchais, L. Ordronneau and H. Le Bozec, Coord. Chem. Rev., 2010, 254, 2533; (c) K. A. Green, M. P. Cifuentes, M. Samoc and M. G. Humphrey, Coord. Chem. Rev., 2011, 255, 2530; (d) S. Di Bella, I. P. Oliveri, A. Colombo, C. Dragonetti, S. Righetto and D. Roberto, Dalton Trans., 2012, 41, 7013; (e) F. Castet, V. Rodriguez, J. L. Pozzo, L. Ducasse, A. Plaquet and B. Champagne, Acc. Chem. Res., 2013, 46, 2656; $(f)$ J. Boixel, V. Guerchais, H. Le Bozec, D. Jacquemin, A. Amar, A. Boucekkine, A. Colombo, C. Dragonetti, D. Marinotto, D. Roberto, S. Righetto and R. De Angelis, J. Am. Chem. Soc., 2014, 136, 5367; (g) J. Boixel, V. Guerchais, H. Le Bozec, A. Chantzis, D. Jacquemin, A. Colombo, C. Dragonetti, D. Marinotto and D. Roberto, Chem. Commun., 2015, 51, 7805.

3 (a) P. C. Ray and P. K. Das, J. Phys. Chem., 1995, 99, 17891;

(b) P. K. Das, J. Phys. Chem. B, 2006, 110, 7621.

4 (a) P. D. Maker, Phys. Rev. A: At., Mol., Opt. Phys., 1970, 1, 923; (b) J. Zyss, J. Chem. Phys., 1993, 98, 6583; (c) K. Clays and A. Persoons, Phys. Rev. Lett., 1991, 66, 2980; (d) J. Zyss and I. Ledoux, Chem. Rev., 1994, 94, 77.

5 L. Sanguinet, J.-L. Pozzo, M. Guillaume, B. Champagne, F. Castet, L. Ducasse and E. Maury, J. Phys. Chem. B, 2006, 110, 10672.

6 F. Mançois, L. Sanguinet, J.-L. Pozzo, M. Guillaume, B. Champagne, V. Rodriguez, F. Adamietz, L. Ducasse and F. Castet, J. Phys. Chem. B, 2007, 111, 9795.

7 F. Mançois, J.-L. Pozzo, J. Pan, F. Adamietz, V. Rodriguez, L. Ducasse, F. Castet, A. Plaquet and B. Champagne, Chem. - Eur. J., 2009, 15, 2560.

8 A. Plaquet, B. Champagne, J. Kulhánek, F. Bureš, E. Bogdan, F. Castet, L. Ducasse and V. Rodriguez, ChemPhysChem, 2011, 12, 3245.

9 E. Cariati, C. Dragonetti, E. Lucenti, F. Nisic, S. Righetto, D. Roberto and E. Tordin, Chem. Commun., 2014, 50, 1608. 10 (a) B. F. Levine and C. G. Bethea, J. Chem. Phys., 1975, 63, 2666; (b) I. Ledoux and J. Zyss, Chem. Phys., 1982, 73, 203.

11 E. Cariati, C. Botta, S. G. Danelli, A. Forni, A. Giaretta, U. Giovanella, E. Lucenti, D. Marinotto, S. Righetto and R. Ugo, Chem. Commun., 2014, 50, 14225.

12 F. Nisic, A. Colombo, C. Dragonetti, D. Roberto, A. Valore, J. M. Malicka, M. Cocchi, G. R. Freeman and J. A. G. Williams, J. Mater. Chem. C, 2014, 2, 1791.

13 V. Balzani, M. Venturi and A. Credi, Molecular Devices and Machines, Wiley-VCH, Weinheim, 2003.

14 (a) D. Marinotto, R. Castagna, S. Righetto, C. Dragonetti, A. Colombo, C. Bertarelli, M. Garbugli and G. Guglielmo, J. Phys. Chem. C, 2011, 115, 20425; (b) D. Marinotto, S. Proutière, C. Dragonetti, A. Colombo, P. Ferruti, D. Pedron, M. C. Ubaldi and S. Pietralunga, J. Non-Cryst. Solids, 2011, 357, 2075; (c) A. Colombo, C. Dragonetti, 
D. Marinotto, S. Righetto, D. Roberto, S. Tavazzi, M. Escadeillas, V. Guerchais, H. Le Bozec, A. Boucekkine and C. Latouche, Organometallics, 2013, 32, 38904.

15 S. R. Meech and D. Phillips, J. Photochem., 1983, 23, 193.

16 See, for example: W. Goodall and J. A. G. Williams, J. Chem. Soc., Dalton Trans., 2000, 2893; R. Krapf, N. P. Illsley, H. C. Tseng and A. S. Verkman, Anal. Biochem., 1988, 169, 142.

17 W. Goodall and J. A. G. Williams, Chem. Commun., 2001, 2514; W. Goodall, K. Wild, K. J. Arm and J. A. G. Williams, J. Chem. Soc., Perkin Trans. 2, 2002, 1669.

18 (a) V. Alain, M. Blanchard-Desce, I. Ledoux-Rak and J. Zyss, Chem. Commun., 2000, 353; (b) F. Tessore, D. Roberto,
R. Ugo, P. Mussini, S. Quici, I. Ledoux-Rak and J. Zyss, Angew. Chem., Int. Ed., 2003, 42, 456; (c) C. Dragonetti, S. Righetto, D. Roberto, R. Ugo, A. Valore, F. Demartin, F. De Angelis, A. Sgamellotti and S. Fantacci, Inorg. Chim. Acta, 2008, 361, 4070; (d) F. Tessore, E. Cariati, F. Cariati, D. Roberto, R. Ugo, P. Mussini, C. Zuccaccia and A. Macchioni, ChemPhysChem, 2010, 11, 495.

19 D. R. Kanis, P. G. Lacroix, M. A. Ratner and T. J. Marks, J. Am. Chem. Soc., 1994, 116, 10089.

20 D. Locatelli, S. Quici, S. Righetto, D. Roberto, F. Tessore, G. J. Ashwell and M. Amiri, Prog. Solid State Chem., 2005, 33, 223. 